\title{
Cerebral Amyloid Angiopathy: Perspectives on Cerebrovascular Dysfunction
}

Andrew W Johnson, Gregory J Zipfel, and Byung H Han*

Department of Neurological Surgery and Hope Center for Neurological Disorders, Washington University in St. Louis, USA

\section{Cerebral Amyloid Angiopathy and Cerebrovascular Dysfunction}

Cerebral amyloid angiopathy (CAA) occurs sporadically in elderly populations or in familial forms of Alzheimer's disease (AD) and is characterized by insoluble deposition of amyloid-beta peptides $(\mathrm{A} \beta)$, within arterial vessels of the central nervous system. Amyloid precursor protein is processed by $\beta$ - and $\gamma$-secretases generating $A \beta_{1-40}$ and $A \beta_{1-42}$ species that exist as soluble monomers, soluble oligomers (toxic intermediate species), and insoluble fibrils (principle component of CAA) [1]. Of interest, the co-morbidity and relationship between vascular compromise and neurodegenerative processes are not fully understood. CAA is an associated risk factor for intracerebral hemorrhage and ischemic stroke and also may contribute to the cognitive decline observed in aging, $\mathrm{AD}$, or both [1]. Most $\mathrm{AD}$ cases feature early decreases in cerebral perfusion that may arise as a consequence of peripheral vascular disease (e.g., type II diabetes, hypertension) and/or loss of basalocortical cholinergic innervation that regulates cerebral blood flow (CBF) among other neurological functions [2]. Much remains to be understood concerning CAA-induced vasomotor impairment and its impact toward the occurrence and/or progression of impaired cognitive function within neurodegenerative disease.

\section{Amyloid Beta, Oxidative Stress, and Vasomotor Function}

The effects of $\mathrm{A} \beta$ on cerebral blood flow are evident in multiple experimental paradigms. Ex vivo studies that examined the functional effects of monomeric $A \beta$ on isolated cerebral arterioles show that synthetic $A \beta 1-40$ (and to a lesser degree $A \beta 1-42$ ) causes direct vessel constriction, enhanced response to vasoconstrictors, and reduced response to vasodilators $[3,4]$. In vivo studies have shown that 6 month-old Tg2576 mice (a common AD model that overexpresses human familial amyloid precursor protein mutation and develops CAA after approximately 12 months of age) have reduced baseline cerebral blood flow and decreased cerebrovascular responses to topical vasodilators [5-7]. Our lab has shown that cortical arterioles of 6 month-old Tg2576 mice have reduced vascular reactivity to hypercapnia and topical vasodilators, and established for the first time that these cerebrovascular deficits are reduced by depleting soluble $A \beta$ via $\gamma$-secretase inhibition [8]. Hence, $A \beta$ species appear to interfere with the vasomotor machinery directly or by induced intermediate factors.

In health tissue endothelium exerts diverse effects within arterial walls of vessels within the brain and on nearby target cells to inhibit vascular tone and vascular growth, protect against thrombosis, and other protective effects [9]. Much of the influence of endothelium on other cells is mediated by intercellular signals carried by diffusible factors, such as nitric oxide (NO) produced by the endothelial form of NO synthase (eNOS). Impairment of eNOS-driven signals underlies vascular dysfunction in a broad spectrum of diseases and is a risk factor for cerebrovascular events and stroke [9]. Reactive oxygen species (ROS) are thought to play a major role in vasomotor dysfunction by efficiently reacting with $\mathrm{NO}$ to form the reactive nitrogen anion peroxynitrite, which in turn wreaks havoc by nitrosylating tyrosine and other amino acid residues on protein substrates affecting important cell signaling and structural interactions [9]. ROS mediated impairment is not limited to the eNOS signaling cascade but may also affect other endothelial-derived factors that play a role in vascular regulation (e.g. endothelial derived hyperpolarizing factor) [9].

Interestingly, monomeric $\mathrm{A} \beta$ species cause a hyper-contractile vascular phenotype in vascular smooth muscle cells (VSMCs) potentiated by ROS-induced endothelial cell (EC) dysfunction, which suggests a strong link between a presumed cause of neuronal cell dysfunction and vascular/blood flow impairment [10,11]. A $\beta$ fibrils and plaques can potentiate oxidative stress, microglial activation and induce vascular dysfunction in the cerebral circulation that contributes to neuronal cell death [12]. Moreover, it has been suggested that $A \beta$ increases NADPH oxidase activity in the vasculature resulting in increased production of highly reactive oxygen species, superoxide [10] (Figure 1).

\section{Cerebral Amyloid Angiopathy and Oxidative Stress}

CAA is seen predominantly in cortical and penetrating cerebral arterioles and is composed predominantly of $A \beta_{1-40}$ [13]. Vascular dysfunction associated with CAA is not simply due to structural changes but may have deleterious effects on both ECs and VSMCs. The effect of soluble vs. insoluble $A \beta$ load on cerebral blood flow is

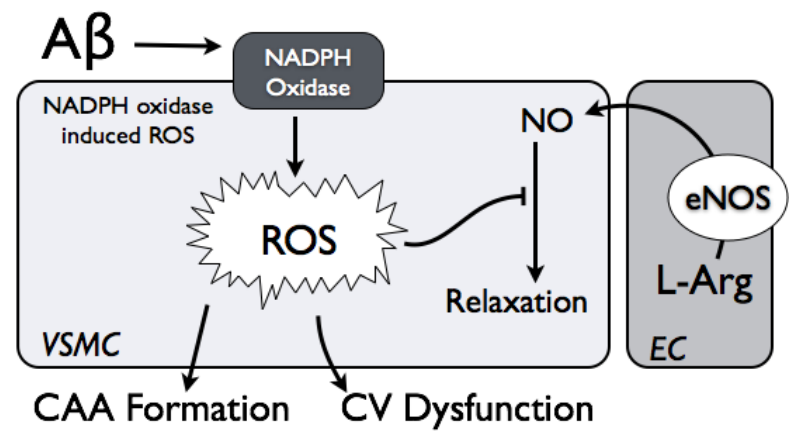

Figure 1: Amyloid beta $(A B)$ induces NADPH oxidases to produce reactive oxygen species (ROS), which leads to (1) cerebrovascular (CV) dysfuction by reducing the bioavailability of nitric oxide (NO) produced by endothelial NO synthase (eNOS) from its substrate L-arginine (L-Arg) and (2) the further deposition of $A \beta$ into insoluble fibers in the form of cerebral amyloid angiopathy (CAA)

*Corresponding author: Byung Hee Han, Department of Neurosurgery Washington University in St. Louis, Campus Box 8057, 660 S. Euclid Ave. St. Louis, MO 63110, USA, E-mail: hanh@wudosis.wustl.edu

Received November 16, 2013; Accepted November 18, 2013; Published November 21, 2013

Citation: Johnson AW, Zipfel GJ, Han BH (2013) Cerebral Amyloid Angiopathy: Perspectives on Cerebrovascular Dysfunction. J Neurol Disord 2: e108. doi:10.4172/2329-6895.1000e108

Copyright: (c) 2013 Johnson AW, et al. This is an open-access article distributed under the terms of the Creative Commons Attribution License, which permits unrestricted use, distribution, and reproduction in any medium, provided the original author and source are credited. 
Citation: Johnson AW, Zipfel GJ, Han BH (2013) Cerebral Amyloid Angiopathy: Perspectives on Cerebrovascular Dysfunction. J Neurol Disord 2: e108. doi:10.4172/2329-6895.1000e108

highly debated, much evidence exists to suggest that soluble $\mathrm{A} \beta$ does affect the functionality of cerebral blood vessels independent of that induced by vascular $\mathrm{A} \beta$ deposits [4,8]. Many studies (but not all [11]) suggest that VSMC dysfunction not only contributes to CAAinduced cerebrovascular impairment and is likely a predominant cellular event. CAA-laden vessels from transgenic mice and humans develop substantial vascular functional impairment and VSMC degeneration in advanced stages of the disease [8]. CAA-induced VSMC-mediated vasomotor dysfunction begins prior to significant VSMC loss, indicating that CAA (or soluble A $\beta$ species in equilibrium with CAA) likely induces cerebral arteriole dysfunction through means outside of direct $A \beta$-induced cytotoxicity [8], which suggests that CAA induces endothelium-independent vessel dysfunction via unidentified molecular effector(s) likely to be ROS. Other gaps in knowledge include the upstream molecules that mediate the $A \beta$-induced vascular dysfunction and may include pro-inflammatory mediators [12].

\section{Potential Therapies}

Anti-amyloid therapies that target both CAA and parenchymal A $\beta$ deposits are of great interest and have lead to numerous strategies and lead compounds. Recent advances in pharmacotherapy include small molecule inhibitors of amyloid precursor protein secretase complexes that inhibit the production of $A \beta$ and humanized monoclonal antibodies recognizing epitopes within primary structure of the $A \beta$ peptide. These strategies have also met unforeseen complications in that within clinical trials of immunotherapies have cleared brain parenchymal $A \beta$, but also increased vascular $A \beta$ deposition increasing the risk of cerebral hemorrhage [14]. Passive immunization with designer antibodies lacking the Fc-receptor activity and do not activate effector cells has been suggested as an approach to effectively target the $A \beta$ burden and avoid detrimental inflammatory effects associated with other immunotherapies [14]. Anti-ROS therapy via ROS scavenger molecules or inhibition of ROS generating enzymes (e.g., NADPH oxidase) in animal models has been successful in ameliorating cardiovascular disease in animal models, but results from human studies are largely disappointing [9]. The impact of anti-ROS therapy on the formation of CAA and related blood vessel function is of great interest in both future animal and human trials. Additionally, new imaging technologies that specifically identify CAA are in current development with the ultimate goal to aid the assessment of the disease classification within patients [15]. It is with great anticipation and effort that we look for the impact that these potential therapies will have on the structural and functional effects of $A \beta$ and CAA on cerebral vasculature.

\section{References}

1. Greenberg SM (2002) Cerebral amyloid angiopathy and vessel dysfunction. Cerebrovasc Dis 13 Suppl 2: 42-47.

2. Girouard H, ladecola $\mathrm{C}$ (2006) Neurovascular coupling in the normal brain and in hypertension, stroke, and Alzheimer disease. J Appl Physiol (1985) 100: 328-335.

3. Thomas T, Thomas G, McLendon C, Sutton T, Mullan M (1996) beta-Amyloidmediated vasoactivity and vascular endothelial damage. Nature 380: 168-171.

4. Niwa K, Porter VA, Kazama K, Cornfield D, Carlson GA, et al. (2001) A betapeptides enhance vasoconstriction in cerebral circulation. Am J Physiol Heart Circ Physiol 281: H2417-H2424.
5. Iadecola C, Zhang F, Niwa K, Eckman C, Turner SK, et al. (1999) Sod1 rescues cerebral endothelial dysfunction in mice overexpressing amyloid precursor protein. Nature Neurosci 2: 157-161.

6. Niwa K, Kazama K, Younkin SG, Carlson GA, ladecola C (2002) Alterations in cerebral blood flow and glucose utilization in mice overexpressing the amyloid precursor protein. Neurobiol Dis 9: 61-68.

7. Niwa K, Younkin L, Ebeling C, Turner SK, Westaway D, et al. (2000) Abeta 1-40-related reduction in functional hyperemia in mouse neocortex during somatosensory activation. Proc Natl Acad Sci U S A 97: 9735-9740.

8. Han BH, Zhou ML, Abousaleh F, Brendza RP, Dietrich HH, et al. (2008) Cerebrovascular dysfunction in amyloid precursor protein transgenic mice: Contribution of soluble and insoluble amyloid-beta peptide, partial restoration via gamma-secretase inhibition. J Neurosci 28: 13542-13550.

9. Faraci FM (2011) Protecting against vascular disease in brain. Am J Physio Heart Circ Physiol 300: H1566-H1582.

10. Dietrich HH, Xiang C, Han BH, Zipfel GJ, Holtzman DM (2010) Soluble amyloid-beta, effect on cerebral arteriolar regulation and vascular cells. Mol Neurodegener 5: 15 .

11. Park L, Zhou P, Pitstick R, Capone C, Anrather J, et al. (2008) Nox2-derived radicals contribute to neurovascular and behavioral dysfunction in mice overexpressing the amyloid precursor protein. Proc Natl Acad Sci U S A 105 $1347-1352$.

12. Hamel E, Nicolakakis N, Aboulkassim T, Ongali B, Tong XK (2008) Oxidative stress and cerebrovascular dysfunction in mouse models of Alzheimer's disease. Exp Physiol 93: 116-120.

13. Zipfel GJ, Han H, Ford AL, Lee JM (2009) Cerebral amyloid angiopathy: progressive disruption of the neurovascular unit. Stroke 40: S16-S19.

14. Wilcock DM, Rojiani A, Rosenthal A, Subbarao S, Freeman MJ, et al. (2004) Passive immunotherapy against abeta in aged app-transgenic mice reverses cognitive deficits and depletes parenchymal amyloid deposits in spite of increased vascular amyloid and microhemorrhage. J Neuroinflammation 1: 24

15. Han BH, Zhou ML, Vellimana AK, Milner E, Kim DH, et al. (2011) Resorufin analogs preferentially bind cerebrovascular amyloid: potential use as imaging ligands for cerebral amyloid angiopathy. Mol Neurodegener 6: 86. 